\title{
Neuronal Size in the Spinal Nucleus of the Bulbocavernosus: Direct Modulation by Androgen in Rats with Mosaic Androgen Insensitivity
}

\author{
Neil V. Watson, ${ }^{1}$ Louise M. Freeman, ${ }^{2}$ and S. Marc Breedlove ${ }^{3}$ \\ ${ }_{1}^{1}$ Department of Psychology, Simon Fraser University, Burnaby, British Columbia, V5A 1 S6 Canada, 2Mary Baldwin \\ College, Staunton, Virginia 24401, and ${ }^{3}$ Department of Psychology, University of California, Berkeley, California 94720
}

The motoneurons of the spinal nucleus of the bulbocavernosus (SNB) and its target muscles, the bulbocavernosus and levator ani, form a sexually dimorphic circuit that is developmentally dependent on androgen exposure and exhibits numerous structural and functional changes in response to androgen exposure in adulthood. Castration of male adult rats causes shrinkage of SNB somata, and testosterone replacement reverses this effect, but the site at which androgen is acting to cause this change is undetermined. We exploited the $\mathrm{X}$-chromosome residency of the androgen receptor (AR) gene to generate androgenized female rats that were heterozygous for the testicular feminization mutant (tfm) AR mutation and that, as a consequence of ontogenetic random $\mathrm{X}$-inactivation, expressed a blend of androgen-sensitive wild-type cells and $t f m$-affected androgen-insensitive cells in the SNB. Chronic testosterone treatment of adult mosaics increased soma sizes only in androgen-competent wild-type SNB cells. The size of $t f m$-affected SNB somata in the same animals did not differ from the size of either the wild-type or tfm-affected SNB neurons in control mosaics that did not receive androgen treatment in adulthood. Because the muscle targets of the SNB are known to be uniformly androgen-sensitive in tfm mosaics, this mosaic analysis provides unambiguous evidence that androgenic effects on motoneuron soma size are mediated locally in the SNB. It is possible that the neuronal AR plays a permissive role in coordinating the actions of androgen.

Key words: mosaic; androgen; spinal nucleus of the bulbocavernosus; tfm mutation; soma size; steroid receptors
Most vertebrate motoneurons possess androgen receptors (ARs) (Pfaff, 1968; Sar and Stumpf, 1977; Kelley, 1986; Simerly et al., 1990), making them attractive models of steroidal effects on neuronal structure and function. The spinal nucleus of the bulbocavernosus (SNB), a cluster of motoneurons located in the dorsomedial aspect of lumbar segments 5 and 6 , innervates the sexually dimorphic perineal muscles bulbocavernosus and levator ani (BC/LA), which participate in copulatory behavior. Adult male rats have more and larger SNB motoneurons than do females (Breedlove and Arnold, 1980, 1981; Schroder, 1980). A perinatal surge of testosterone $(\mathrm{T})$ in males rescues the $\mathrm{BC} / \mathrm{LA}$ musculature from involution (Cihak et al., 1970) and inhibits apoptosis in the SNB (Nordeen et al., 1985). Exposing females to exogenous androgens during this critical period permanently masculinizes the SNB-BC/LA system (Breedlove and Arnold, 1983). The SNB critical period developmentally precedes AR expression in SNB cells (Jordan et al., 1991), and systemic androgen can rescue genetically androgen-insensitive SNB motoneurons provided that their $\mathrm{BC} / \mathrm{LA}$ targets remain androgencompetent (Freeman et al., 1996). Furthermore, androgen is unable to rescue the SNB if the $\mathrm{BC} / \mathrm{LA}$ muscles are treated with anti-androgen (Fishman and Breedlove, 1992) or extirpated (Kurz et al., 1992), indicating that androgen acts indirectly, via actions in the $\mathrm{BC} / \mathrm{LA}$, to rescue the SNB.

\footnotetext{
Received June 14, 2000; revised Nov. 9, 2000; accepted Nov. 21, 2000.

This study was supported by Natural Sciences and Engineering Research Council of Canada Grant OGP0194522 (to N.V.W.) and National Institutes of Health Grant NS28421 (to S.M.B.). We thank Dr. Cynthia L. Jordan (University of California, Berkeley) for her many generous technical and conceptual contributions.

Correspondence should be addressed to Dr. Neil V. Watson, Department of Psychology, Simon Fraser University, 8888 University Drive, Burnaby, British Columbia, V5A 1S6 Canada. E-mail: nwatson@sfu.ca.

Copyright (C) 2001 Society for Neuroscience 0270-6474/01/211062-05\$15.00/0
}

SNB motoneurons shrink in castrated adults, and testosterone reverses this effect (Breedlove and Arnold, 1981; Collins et al., 1992). Somatic enlargement is associated with increased rates of gene transcription (Beato, 1989), and SNB somatic enlargement presumably reflects genomic events involved in neuronal remodeling, such as process outgrowth (Bleisch and Harrelson, 1989). Interestingly, systemic androgens do not enlarge motoneurons innervating the sexually monomorphic external urethral sphincter, although their AR density is comparable with that of SNB motoneurons (Jordan, 1997). This suggests that ARs are necessary but not sufficient to confer androgen sensitivity on neurons, highlighting a longstanding problem concerning the site of action of steroids in vivo. Steroids are lipid soluble and widespread, and their cognate receptors are found throughout the body. An observed effect of androgen on a population of neurons may therefore be mediated directly by intraneuronal AR or indirectly via sites afferent or efferent to the motoneurons under study. Examples of indirect actions include the muscle-dependent ontogenetic sparing of the masculine SNB and, in the adult, BC/ LA-mediated androgenic regulation of SNB dendritic extent (Rand and Breedlove, 1995) and AR content (Lubischer and Arnold, 1995a).

Neuronal ARs have been studied in vitro (Brooks et al., 1998), but culture techniques are necessarily mute regarding the site of androgenic action in the intact animal. The most powerful way to resolve this site-of-action indeterminacy at the cellular level would be through genetic mosaic analysis, creating animals exhibiting a blend of normal neurons and mutant, steroidincompetent neighbors in regions that are normally uniformly androgen-sensitive. We now report such a mosaic analysis of androgenic regulation of SNB soma size. 


\section{MATERIALS AND METHODS}

Mosaic animals. Mosaic animals were generated by capitalizing on the residence of the AR gene on the X chromosome (Yarbrough et al., 1990). As a consequence of the mammalian process of embryonic random X-chromosome inactivation (Lyon, 1961; Monk and Harper, 1979), perinatally androgenized female rats that are heterozygous for the testicular feminization mutant $(t f m)$ AR mutation $\left(\mathrm{X}^{t f m} \mathrm{X}\right)$ possess masculinized SNB systems that are a phenotypic mosaic of neurons containing normal, steroid-competent wild-type (WT) AR and $t f m$-affected neurons in which $\sim 90 \%$ of the AR is incompetent to bind androgen. We have recently exploited this mosaic in studies of apoptosis and regulation of calcitonin gene-related peptide (CGRP) expression and have described the mosaic model more fully previously (Freeman et al., 1996; Monks et al., 1999). Because they differ only in androgen receptor competency, the $t \mathrm{fm}$-affected and wild-type cells of mosaics would be expected to have equivalent soma sizes in the absence of androgens. After chronic treatment with systemic androgen, however, two outcomes are possible. If the effects of androgens on SNB soma size are mediated indirectly, via neighboring neurons or target muscles, then both cell types should respond to systemic androgen by enlarging. Conversely, if androgens act directly on SNB neurons to alter their structure, then only the steroidcompetent WT neurons should show plastic changes in response to systemic androgens.

Carrier females from our colony $\left(\mathrm{XX}^{t f m}\right)$, previously identified by having given birth to $t f m$-affected males, were paired with wild-type males, and the day of sperm-positive vaginal lavage was denoted as embryonic day 1 (E1). On days E16-E20, the pregnant dams received systemic injections of testosterone propionate (TP) $(2.0 \mathrm{mg}$, s.c., dissolved in $0.1 \mathrm{ml}$ of sesame oil). Because androgen treatment sometimes interferes with parturition, the pups were delivered by cesarean section on E23. Pregnant dams were anesthetized with ether, and immediately after the pups were delivered via abdominal and uterine incisions, the dam was killed by an overdose of sodium pentobarbital. The pups were cleaned, dried, and warmed, and each received an injection of TP (1.0 $\mathrm{mg}$, s.c.). They were then cross-fostered to another lactating wild-type female and received a final injection of TP $(1.0 \mathrm{mg}$, s.c. $)$ on postnatal day 3 (P3), with day of delivery considered P1. This regimen of prenatal and postnatal testosterone injections served two purposes. First, it served to masculinize the SNB-BC/LA system and maximally rescue SNB motoneurons from apoptosis (Freeman et al., 1996; Ward et al., 1996). Second, it provided a means to distinguish androgenized wild-type females, who do not form nipples in the presence of prenatal testosterone (Goldman et al., 1976), from mosaics (androgenized $t f m$ carriers), who form nipples despite prenatal androgen exposure because of the presence of androgen-insensitive nipple tissue (Freeman et al., 1996).

The androgenized pups were weaned on P30, and the genotype of each pup was determined according to the system of phenotypic markers described by Freeman et al. (1996). Briefly, males with scrotal or inguinal testes and no nipples were classified as wild-type males, whereas those with inguinal testes and intact nipples were classified as $t \mathrm{fm}$-affected males. Animals lacking both testes and nipples were classified as masculinized wild-type females, and animals lacking testes but with intact nipples were classified as $t \mathrm{fm}$ mosaics. At the conclusion of the experiment, gonadal sex was confirmed for each experimental animal through dissection of the reproductive tract.

Hormonal manipulations. At $60-90 \mathrm{~d}$ of age, a total of $16 \mathrm{tfm}$ mosaics received two $20 \mathrm{~mm}$ SILASTIC implants $(3.18 \mathrm{~mm}$ outer diameter, 1.57 $\mathrm{mm}$ inner diameter) packed with crystalline testosterone, constructed as described by Smith et al. (1977). Implants of this size maintain serum levels of testosterone in a high physiological range for male rats (Smith et al., 1977). A total of $13 \mathrm{tfm}$ mosaics received two $20 \mathrm{~mm}$ empty SILASTIC implants. Implants were placed subcutaneously between the scapulae under metofane anesthesia, via a small skin incision. After recovery, the mosaics were returned to normal colony housing on a $12 \mathrm{hr}$ light/dark cycle.

SILASTIC implants were left in place for 4-6 weeks and then removed under metofane anesthesia. After an additional $24-48 \mathrm{hr}$, all animals received an injection of hydroxy-flutamide (OH-fl) $(2.0 \mathrm{mg}$ in 0.1 $\mathrm{ml}$ of propylene glycol, s.c.; a generous gift from Dr. R. Neri, ScheringPlough Research Institute, Union, NJ). OH-fl is an AR ligand that induces translocation of functional androgen receptors to the cell nucleus, apparently without inducing gene transcription (Kemppainen et al., 1992; Zhou et al., 1994). This facilitates the use of androgen receptor immunocytochemistry (ICC) to distinguish between $\mathrm{tfm}$-affected motoneurons and wild-type motoneurons in the SNB. After OH-fl treat- ment, most wild-type neurons exhibit nuclear labeling of AR, but most tfm-affected cells do not (Freeman et al., 1996; Monks et al., 1999).

Perfusion and tissue preparation. Between 2 and $4 \mathrm{hr}$ after the $\mathrm{OH}-\mathrm{fl}$ injection, animals received an overdose of sodium pentobarbital $(\sim 100$ $\mathrm{mg} / \mathrm{kg}$, i.p.). On attainment of surgical anesthesia (indicated by the disappearance of deep reflexes), each animal was perfused transcardially

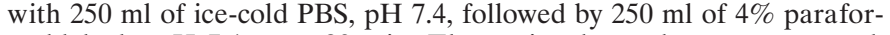
maldehyde, $\mathrm{pH} 7.4$, over $20 \mathrm{~min}$. The perineal muscles were removed, trimmed, blotted dry, and weighed. The lumbar spinal cord containing the SNB was dissected out, post-fixed in $4 \%$ paraformaldehyde for $2 \mathrm{hr}$, and then transferred to a $20 \%$ buffered sucrose solution. The following day, the lumbosacral segments were frozen and sectioned coronally at a thickness of $50 \mu \mathrm{m}$ on a sliding microtome, into three series of sequential sections. One series consisting of every third section was processed for AR immunoreactivity, and a second such series was processed without the primary antibody as a control for any nonspecific labeling. The third series was stored in cryoprotectant at $-20^{\circ} \mathrm{C}$ as a backup.

Immunocytochemistry. All reactions were performed at room temperature unless otherwise indicated. Free-floating spinal cord sections received three 10 min washes in a phosphate-buffered gelatin Triton solution (PBS-GT) $(0.1 \%$ gelatin and $0.3 \%$ Triton X-100, in PBS, $\mathrm{pH}$ 7.4). The sections were then incubated first in $10 \%$ normal goat serum (NGS) for $1 \mathrm{hr}$, to block nonspecific binding of the secondary antibody, and then for $48 \mathrm{hr}$ at $4{ }^{\circ} \mathrm{C}$ in a solution consisting of $4 \%$ NGS and 0.167 $\mu \mathrm{g} / \mathrm{ml}$ PG21, a rabbit polyclonal antibody directed against the 21 amino acid C-terminal epitope of the AR (a generous gift from Dr. G. Prins, University of Chicago, Chicago, IL). PG21 has been characterized previously in the SNB in the tfm mosaic preparation (Freeman et al., 1996; Monks et al., 1999) and has been found to effectively discriminate between wild-type motoneurons, which exhibit dense nuclear AR immunoreactivity, and $t f m$-affected motoneurons, which exhibit no nuclear AR immunoreactivity and only light, diff use cytoplasmic labeling. After incubation with PG21, sections were washed in PBS-GT, treated with avidin-biotin blocking reagents (Vector Laboratories, Burlingame, CA), washed again, and incubated for $1 \mathrm{hr}$ in biotinylated goat anti-rabbit secondary antibody. Tissue was then washed and incubated in avidinbiotin-peroxidase complex (Vector Laboratories) for $1 \mathrm{hr}$, and immunolabeling was subsequently visualized using $3,3^{\prime}$-diaminobenzidine in the presence of hydrogen peroxide and nickel chloride in $0.1 \mathrm{M}$ Tris buffer, $\mathrm{pH} 7.2$, yielding a dense blue-black reaction product. Tissue was then washed, mounted on gel-subbed slides, and coverslipped after dehydration through graded alcohols and clearing in xylene.

Motoneuronal soma size. Slides of AR-labeled sections were mounted on a light microscope, and an experimenter blind to experimental condition made a drawing of each section and mapped the locations of apparent AR-positive SNB motoneuron nuclei, using a camera lucida attachment. The putative SNB nuclei were evident as large dark circles against a light background in the ventromedial aspect of the spinal cord (Fig. 1). Control sections processed without the primary antibody were devoid of labeling, as expected, and were not processed further.

Coverslips were subsequently soaked off in xylene, and the tissue was rehydrated through graded alcohols, counterstained with Neutral Red Nissl stain, and recoverslipped. The previously mapped nuclei were confirmed to belong to SNB motoneurons, which were identified by their large size, location, and dark Nissl stain. The somatic margins of a random sample of 20 such wild-type cells were drawn for each mosaic using the camera lucida attachment. The counterstain also revealed the $t f m$-affected SNB motoneurons that lacked nuclear immunolabeling, and the somatic margins of a random sample of 20 such cells were traced for each mosaic. In cases in which 20 cells of either type were not present, all available motoneurons were traced. A minority of cells exhibited faint nuclear labeling and were excluded from further analysis because of their ambiguous identity. The camera lucida drawings were then digitized and transferred to a microcomputer, and the areas of the somata were calculated.

Separate groups of mosaics were prepared and analyzed by two independent experimenters in a test-and-replication design; the obtained data were analyzed using $2 \times 2$ factorial ANOVA for hormone treatment (blank vs T) by cell type ( $f f m$ vs wild-type cells, treated as a withinsubjects factor). Subsequent planned comparisons of group means were performed using $t$ tests.

\section{RESULTS}

Treatment of adult mosaics with testosterone-filled implants greatly increased the mass of the BC/LA musculature $(214 \pm 16$ 

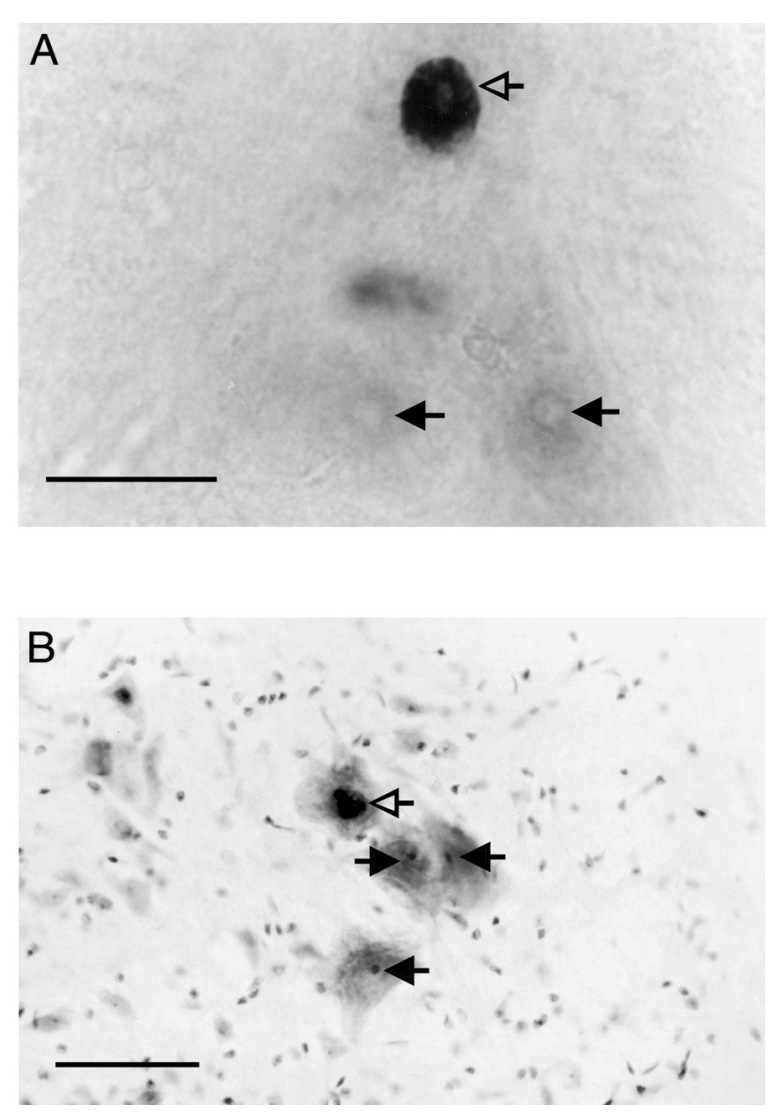

Figure 1. A, Varied androgen receptor distribution in the SNB of the $t f m$ mosaic, as revealed by AR ICC without Nissl counterstain. Open arrow indicates a wild-type motoneuron exhibiting dense nuclear androgen receptor ICC label. Filled arrows indicate tfm-affected motoneurons, identifiable by their lack of nuclear androgen receptor label; the nucleoli are visible and mark the location of the nuclei. In wild-type animals, virtually all SNB motoneurons exhibit the wild-type pattern of dense nuclear AR immunolabeling. Scale bar, $50 \mu \mathrm{m}$. $B$, Nissl counterstain of AR ICC material permits measurement of the somata of SNB cells with (open arrow) or without ( filled arrows) nuclear AR. Scale bar, $100 \mu \mathrm{m}$.

$\mathrm{mg})$ compared with blank-implanted mosaics $(87 \pm 17 \mathrm{mg} ; p<$ 0.01 ), confirming the effectiveness of the steroid manipulation. Chronic testosterone treatment induced an increase in soma size only in AR-immunopositive motoneurons (Fig. 2). The overall effect, a significant interaction effect of cell type and hormone treatment, was virtually identical in the initial experiment $\left(F_{(1,14)}\right.$ $=8.27 ; p<0.05)$ and in the independent replication experiment $\left(F_{(1,11)}=4.70 ; p<0.05\right)$. In fact, the data obtained in the initial and replication experiments did not differ statistically in any respect and were therefore pooled for subsequent analyses (Fig. $2)$. As expected, the overall effect was significant $\left(F_{(1,27)}=12.05\right.$; $p<0.05)$, and subsequent planned comparisons determined that the mean soma size of the wild-type cells of androgen-treated mosaics was significantly greater than the soma size of the $t f m$ affected cells of those same mosaics $\left(t_{(15)}=5.8 ; p<0.001\right)$, as well as both the wild-type cells $\left(t_{(27)}=2.9 ; p=0.007\right)$ and $t \mathrm{fm}$ cells $\left(t_{(27)}=3.6 ; p<0.001\right)$ of the blank-treated mosaics. The soma sizes of the $t \mathrm{fm}$ cells of the androgen-treated mosaics and the $t f m$ and wild-type cells of the blank-treated mosaics did not differ from one another (all $p$ values $>0.05$ ).

\section{DISCUSSION}

The results of the mosaic analysis indicate that androgens can induce an increase in soma size only in those SNB motoneurons

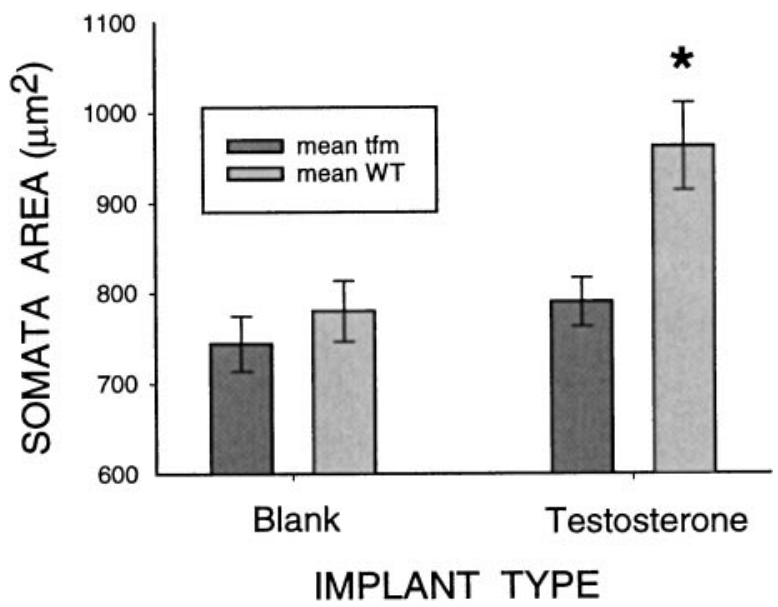

Figure 2. Effect of androgen treatment on SNB soma size in $t f m$ mosaics. Androgen-competent wild-type cells that were exposed to testosterone exhibited significantly enlarged somata relative to all other groups. Other groups did not differ from one another. See Results for details.

that possess functional androgen receptors. The motoneurons themselves are therefore the site of action of androgen in this response. The finding that $\mathrm{tfm}$ cells in T-treated mosaics are no larger than the wild-type cells of blank-treated mosaics further suggests that a direct action on the SNB motoneurons is the major route by which androgenic neuronal enlargement occurs; any extra-SNB effects of androgen on soma size would be evident in the T-treated $\mathrm{tfm}$ cells. The results thus provide a clear demonstration that steroids can act directly on mammalian neurons, in vivo, to induce changes in their structure.

Although our results suggest that competent, ligand-bound AR within SNB cells is required for them to enlarge in response to androgen, previous reports have instead implicated the muscular targets of the SNB as the site of action in this regulation. For example, the ability of SNB motoneurons to enlarge in response to androgen is reportedly impaired when their axonal connections with the $\mathrm{BC} / \mathrm{LA}$ muscles are severed (Lubischer and Arnold, 1995b) and remains low if the severed axons are forced to reinnervate a different, sexually monomorphic muscle (Araki et al., 1991). These findings are not necessarily incompatible with a motoneuronal site of action. For instance, contact with the target muscle may be necessary for SNB motoneurons to maintain normal levels of AR, presumably through the actions of trophic factors (Al-Shamma and Arnold, 1997). The SNB motoneurons of long-term castrates exhibit high levels of AR that may be visualized over the cell nuclei as little as 30 min after androgen injection (Freeman et al., 1995), a time course that is too brief for the production of new ARs. These findings suggest that levels of $\mathrm{AR}$ in the SNB are maintained through an indirect, ARindependent mechanism. Furthermore, systemic androgen treatment reportedly induces correlated increases in both dendritic extent and soma size in the SNB (Sasaki and Arnold, 1991), but when androgen treatment is limited to the BC/LA target muscles, the dendritic outgrowth but not the somatic enlargement is observed (Rand and Breedlove, 1995). This pattern of results is consistent with a permissive role of SNB neuronal AR in regulating soma size.

A criticism that has been leveled at studies using transgenic and knock-out preparations, and which might thereby also apply to the $t f m$ mosaic model, is that we cannot be certain what the cumulative ontogenetic consequences of the absence of a partic- 
ular gene may be and that, by adulthood, the affected cells (or animal) may differ in many respects from the wild type (Routtenberg, 1995). In the case of the $\mathrm{tfm}$ mosaic, it might thus be argued that, because they have been without a functional AR gene since the early embryonic stage of $\mathrm{X}$ inactivation, the $\mathrm{tfm}$ cells may have developed completely different connections and physiology, and that it is these differences that account for their failure to respond to adult androgen treatment. Based on the considerable knowledge of SNB ontogeny that has accrued, we think this is unlikely. First, it has been well established that SNB motoneurons do not express ARs until comparatively late in development, around the seventh day of postnatal life (Jordan et al., 1991). Any deviation from the normal developmental trajectory attributable to the absence of ARs would have to occur late in postnatal development, by which time the SNB has already made its connections into the periphery, has received its supraspinal projections, and has completed the process of apoptosis. Furthermore, these mosaics are androgenized XX animals that, unlike gonadally intact males, had very little circulating androgen after the first week of life. In the absence of ligand, it is not clear how the $t f m$ and WT cells could subsequently be affected by the presence or absence of functional AR. Significant differences in androgen exposure between the two cell types would thus be limited to the $28 \mathrm{~d}$ treatment period in adulthood; although changes in synaptic connectivity can be provoked by androgen treatment in a matter of days, it is unclear whether this would contribute to cell-type differences in soma size (Leedy et al., 1987). It is also unlikely that the adrenal glands are a significant source of androgenic stimulation in the mosaic SNB, because WT and TFM SNB cells do not differ in size in the blank-treated mosaics; if significant levels of adrenal androgens were present, we would expect the WT cells to be selectively enlarged in this group.

A related concern pertains to the androgen sensitivity of the $\mathrm{BC} / \mathrm{LA}$ muscle targets: if wild-type SNB motoneurons connect exclusively to wild-type androgen-sensitive muscle fibers and $t f m$ affected neurons connect exclusively to $\mathrm{t} f \mathrm{~m}$-affected androgeninsensitive muscle fibers, then our pattern of results might simply be attributable to differential steroid sensitivity of the targets. We have several reasons to believe that this is not the case, and that in fact the $t \mathrm{fm}$ and WT neurons are connected to equivalently androgen-sensitive targets. First, we have previously applied AR ICC to the BC/LA muscle of mosaics and found that approximately one-third of muscle nuclei are AR-positive, which is approximately the same proportion found in wild-type BC/LA (Freeman et al., 1996). Second, muscle fibers are multinucleated cells, and we have never observed a BC/LA muscle fiber in mosaics completely lacking AR-immunoreactive nuclei. Third, each SNB motoneuron innervates, on average, hundreds of muscle fibers (Jordan et al., 1992), and individual BC/LA muscle fibers receive polyneural innervation from the SNB (Jordan et al., 1989), making it unlikely that any SNB motoneuron could fail to be in contact with AR-competent muscle fibers.

Steroidal regulation of gene expression in SNB motoneurons has received considerable attention in recent years as a means of probing basic processes in neuronal physiology and plasticity. Alterations in androgen exposure have been reported to alter motoneuronal transcription-translation rates for numerous gene products; examples include structural proteins such as $\beta$-actin and $\beta$-tubulin (Matsumoto et al., 1994), synaptic components such as the gap junction protein connexin 32 (Matsumoto et al., 1991), signaling peptides such as CGRP (Popper and Micevych, 1989), and various components of neurotrophin systems such as CNTF receptors (Forger et al., 1998). Androgenic changes in dendritic extent and soma size in the SNB, with their associated changes in synaptic connectivity, attest to the functional importance of the androgenic signal. The absence of information about the site of action of androgen in regulating these genes and their products has hindered understanding of the physiological role of these genes and their products and the cellular basis of the actions of androgen in the CNS. The tfm mosaic model extends the resolution of in vivo experimentation from the level of gross tissue events down to the level of cellular events. With the present report, we have now applied the mosaic model to each of three major areas of study: apoptosis (Freeman et al., 1996), regulation of gene product (Monks et al., 1999), and regulation of cellular characteristics. To date, mosaic analysis has not been applied to steroid-sensitive systems outside of the SNB; such studies may prove valuable in uncovering the role of steroids in the development and maintenance of sexual dimorphism elsewhere in the nervous system.

\section{REFERENCES}

Al-Shamma HA, Arnold AP (1997) Brain-derived neurotrophic factor regulates expression of androgen receptors in perineal motoneurons. Proc Natl Acad Sci USA 94:1521-1526.

Araki I, Harada Y, Kuno M (1991) Target-dependent hormonal control of neuron size in the rat spinal nucleus of the bulbocavernosus. J Neurosci 11:3025-3033.

Beato M (1989) Gene regulation by steroid hormones. Cell 56:335-344.

Bleisch WV, Harrelson A (1989) Androgens modulate endplate size and $\mathrm{ACh}$ receptor density at synapses in rat levator ani muscle. J Neurobiol 20:189-202.

Breedlove SM, Arnold AP (1980) Hormone accumulation in a sexually dimorphic motor nucleus of the rat spinal cord. Science 210:564-566.

Breedlove SM, Arnold AP (1981) Sexually dimorphic motor nucleus in the rat lumbar spinal cord: response to adult hormone manipulation, absence in androgen-insensitive rats. Brain Res 225:297-307.

Breedlove SM, Arnold AP (1983) Hormonal control of a developing neuromuscular system. II. Sensitive periods for the androgen-induced masculinization of the rat spinal nucleus of the bulbocavernosus. J Neurosci 3:424-432.

Brooks BP, Merry DE, Paulson HL, Lieberman AP, Kolson DL, Fischbeck KH (1998) A cell culture model for androgen effects in motor neurons. J Neurochem 70:1054-1060.

Cihak R, Gutmann E, Hanzlikova V (1970) Involution and hormoneinduced persistence of the M. sphincter (levator) ani in female rats. $\mathrm{J}$ Anat 106:93-110.

Collins WF, Seymour AW, Klugewicz SW (1992) Differential effect of castration on the somal size of pudendal motoneurons in the adult male rat. Brain Res 577:326-330.

Fishman RB, Breedlove SM (1992) Local perineal implants of antiandrogen block masculinization of the spinal nucleus of the bulbocavernosus. Brain Res Dev Brain Res 70:283-286.

Forger NG, Wagner CK, Contois M, Bengston L, MacLennan AJ (1998) Ciliary neurotrophic factor receptor $\alpha$ in spinal motoneurons is regulated by gonadal hormones. J Neurosci 18:8720-8729.

Freeman LM, Padgett BA, Prins GS, Breedlove SM (1995) Distribution of androgen receptor immunoreactivity in the spinal cord of wild-type, androgen-insensitive, and gonadectomized male rats. J Neurobiol 27:51-59.

Freeman LM, Watson NV, Breedlove SM (1996) Androgen spares androgen-insensitive motoneurons from apoptosis in the spinal nucleus of the bulbocavernosus in rats. Horm Behav 30:424-433.

Goldman AS, Shapiro B, Neumann F (1976) Role of testosterone and its metabolites in the differentiation of the mammary gland in rats. Endocrinology 99:1490-1495.

Jordan C (1997) Androgen receptor (AR) immunoreactivity in rat pudendal motoneurons: implications for accessory proteins. Horm Behav $32: 1-10$.

Jordan CL, Letinsky MS, Arnold AP (1989) The role of gonadal hormones in neuromuscular synapse elimination in rats. II. Multiple innervation persists in the adult levator ani muscle after juvenile androgen treatment. J Neurosci 9:239-247.

Jordan CL, Breedlove SM, Arnold AP (1991) Ontogeny of steroid accumulation in spinal lumbar motoneurons of the rat: implications for androgen's site of action during synapse elimination. J Comp Neurol 313:441-448.

Jordan CL, Pawson PA, Arnold AP, Grinnell AD (1992) Hormonal 
regulation of motor unit size and synaptic strength during synapse elimination in the rat levator ani muscle. J Neurosci 12:4447-4459.

Kelley DB (1986) Neuroeffectors for vocalization in Xenopus laevis: hormonal regulation of sexual dimorphism. J Neurobiol 17:231-248.

Kemppainen JA, Lane MV, Sar M, Wilson EM (1992) Androgen receptor phosphorylation, turnover, nuclear transport, and transcriptional activation. Specificity for steroids and antihormones. J Biol Chem 267:968-974.

Kurz EM, Cover AR, Sengelaub DR (1992) Testosterone fails to save androgen-sensitive rat motoneurons following early target removal. Brain Res Dev Brain Res 70:181-189.

Leedy MG, Beattie MS, Bresnahan JC (1987) Testosterone-induced plasticity of synaptic inputs to adult mammalian motoneurons. Brain Res 424:386-390.

Lubischer JL, Arnold AP (1995a) Evidence for target regulation of the development of androgen sensitivity in rat spinal motoneurons. Dev Neurosci 17:106-117.

Lubischer JL, Arnold AP (1995b) Axotomy of developing rat spinal motoneurons: cell survival, soma size, muscle recovery, and the influence of testosterone. J Neurobiol 26:225-240.

Lyon MF (1961) Gene action in the X chromosome of the mouse (Mus musculus L.). Nature 190:372-373.

Matsumoto A, Arai Y, Urano A, Hyodo S (1991) Androgen regulates gap junction mRNA expression in androgen-sensitive motoneurons in the rat spinal cord. Neurosci Lett 131:159-162.

Matsumoto A, Arai Y, Urano A, Hyodo S (1994) Androgen regulates gene expression of cytoskeletal proteins in adult rat motoneurons. Horm Behav 28:357-366.

Monk M, Harper MI (1979) Sequential X chromosome inactivation coupled with cellular differentiation in early mouse embryos. Nature 281:311-313

Monks DA, Vanston CM, Watson NV (1999) Direct androgenic regulation of calcitonin gene-related peptide expression in motoneurons of rats with mosaic androgen insensitivity. J Neurosci 19:5597-5601.

Nordeen EJ, Nordeen KW, Sengelaub DR, Arnold AP (1985) Andro- gens prevent normally occurring cell death in a sexually dimorphic spinal nucleus. Science 229:671-673.

Pfaff DW (1968) Autoradiographic localization of radioactivity in rat brain after injection of tritiated sex hormones. Science 161:1355-1356.

Popper P, Micevych PE (1989) The effect of castration on calcitonin gene-related peptide in spinal motor neurons. Neuroendocrinology 50:338-343.

Rand MN, Breedlove SM (1995) Androgen alters the dendritic arbors of SNB motoneurons by acting upon their target muscles. J Neurosci 15:4408-4416.

Routtenberg A (1995) Knockout mouse fault lines. Nature 374:314-315.

Sar M, Stumpf WE (1977) Androgen concentration in motor neurons of cranial nerves and spinal cord. Science 197:77-79.

Sasaki M, Arnold AP (1991) Androgenic regulation of dendritic trees of motoneurons in the spinal nucleus of the bulbocavernosus: reconstruction after intracellular iontophoresis of horseradish peroxidase. J Comp Neurol 308:11-27.

Schroder HD (1980) Organization of the motoneurons innervating the pelvic muscles of the male rat. J Comp Neurol 192:567-587.

Simerly RB, Chang C, Muramatsu M, Swanson LW (1990) Distribution of androgen and estrogen receptor mRNA-containing cells in the rat brain: an in situ hybridization study. J Comp Neurol 294:76-95.

Smith ER, Damassa DA, Davidson JM (1977) Hormone administration: peripheral and intracranial implants. In: Methods in psychobiology (Meyers RD, ed), pp 259-278. New York: Academic.

Ward OB, Wexler AM, Carlucci JR, Eckert MA, Ward IL (1996) Critical periods of sensitivity of sexually dimorphic spinal nuclei to prenatal testosterone exposure in female rats. Horm Behav 30:407-415.

Yarbrough WG, Quarmby VE, Simental JA, Joseph DR, Sar M, Lubahn DB, Olsen KL, French FS, Wilson EM (1990) A single base mutation in the androgen receptor gene causes androgen insensitivity in the testicular feminized rat. J Biol Chem 265:8893-8900.

Zhou ZX, Wong CI, Sar M, Wilson EM (1994) The androgen receptor: an overview. Recent Prog Horm Res 49:249-274. 